\title{
Visualization of Carotid Doppler in Patients with Ischemic Stroke at Dr. Hasan Sadikin General Hospital Bandung Year 2016-2019
}

\author{
Olivia, ${ }^{1}$ Ahmad Rizal Ganiem, ${ }^{2}$ Syarief Hidayat ${ }^{3}$ \\ ${ }^{1}$ Faculty of Medicine Universitas Padjadjaran, Indonesia, ${ }^{2}$ Department of Neurology Faculty \\ of Medicine Universitas Padjadjaran/Dr. Hasan Sadikin General Hospital Bandung, Indonesia, \\ ${ }^{3}$ Department of Cardiology and Vascular Medicine Faculty of Medicine Universitas Padjadjaran/ \\ Dr. Hasan Sadikin General Hospital Bandung, Indonesia
}

\section{Abstract}

Background: Various pathological changes in both the intra and extracranial arteries that supply the brain can cause disturbance of cerebral blood flow and perfusion leading to cerebral dysfunction. Doppler ultrasound is able to assess these changes. This study was performed to evaluate the anatomical and physiological changes found in the carotid arteries of patients with ischemic stroke using Doppler ultrasound.

Methods: The cross-sectional descriptive study design with total sampling method was conducted on the medical records of ischemic stroke patients who had carotid Doppler ultrasound at the Department of Cardiology and Vascular Medicine Dr. Hasan Sadikin General Hospital Bandung from 2016 to 2019. Demographic data, such as stroke diagnoses and plaque characteristics recorded in the Doppler reports were collected.

Results: There were 38 data sets collected. The distribution and characteristics of atherosclerotic plaques were similar between the two carotid systems, with the same percentage of plaque being found in the right (31.6\%) and left (36.8\%) carotid system. The most common type of plaque found was type III and was located in the common carotid artery. Thrombus was absent in all patients. Intimal media thickening was found in $13.2 \%$ right system and 15.8\% left system. Stenosis was present in $34.2 \%$ of patients, and most had $<50 \%$ stenosis. Peak systolic velocity increased $(>125 \mathrm{~cm} / \mathrm{s})$ in $5.3 \%$ of the right system and $7.9 \%$ of the left system of the internal carotid artery.

Conclusions: Most of the atherothrombotic and thromboembolic type of ischemic stroke patients in this study have normal carotid Doppler ultrasound features. Further study on the presence of plaque in ischemic stroke patients in Indonesia is needed.

Keywords: Atherosclerotic plaque, carotid doppler ultrasound, ischemic stroke

\section{Introduction}

Stroke is a non-communicable disease that has been known as the primary cause of disability and vascular death worldwide. ${ }^{1}$ The World Health Organization (WHO) defines stroke as rapidly developing clinical signs of focal or global disturbance of cerebral function, lasting more than 24 hours or leading to death, with no apparent cause other than vascular origin, and classified into ischemic and hemorrhagic types. $^{2}$ Nationally, the 2018 Basic Health Research (Riset Kesehatan Dasar, Riskesdas) reported that the prevalence of stroke in
Indonesia was 10.9 per 1,000 population. ${ }^{3}$

Blood flow to brain region in ischemic stroke patients is disrupted due to pathological changes that occur in blood vessels, mainly caused by advanced atherosclerotic plaques. These plaques may rupture and form a thrombus, which can then become the source of embolus, both of which lead to arterial occlusion resulting in territorial infarcts of variable size. ${ }^{4}$ These arterial pathological changes, both plaque morphological characteristics and blood flow, can be observed using a widely available, economical, noninvasive imaging modality, namely Doppler

Correspondence: Olivia, Faculty of Medicine Universitas Padjadjaran, Jalan Raya Bandung Sumedang Km. 21 Jatinangor, Sumedang Indonesia, Email: livolivia3@gmail.com 
ultrasound. ${ }^{5,6}$

Pathological changes that occur in the carotid artery as the site of symptomatic lesions most often occur in ischemic stroke patients using Doppler ultrasound. ${ }^{7}$ Therefore, this study aimed to evaluate anatomical and physiological changes found in the carotid arteries of patients with ischemic stroke using Doppler ultrasound.

\section{Methods}

This was a descriptive cross-sectional study. Secondary data were collected from medical records of the patients at the Department of Cardiology and Vascular Medicine, Dr. Hasan Sadikin General Hospital Bandung, from January 2016 to December 2019. Inclusion criteria were adult patient $>18$ years, diagnosed with atherothrombotic or thromboembolic stroke in the carotid system, and underwent carotid Doppler ultrasound examination. Patients with incomplete data were excluded from the study.

The data collected in this study were age, gender, stroke location (left or right carotid system), anatomical assessment, and functional assessment of carotid Doppler examination. Anatomical assessment included plaque characteristics (presence, location, and type), presence of thrombus, intimal media thickening, and degree of carotid artery stenosis which were then classified into six categories (<50\%, 50-70\%, 70-95\%, 90-95\%, >95\%, no stenosis). Plaque echogenicity was classified as pure hypoechoic (type I), hypoechoic with a small hyperechoic area (type II), hyperechoic with a small hypoechoic area (type III), and hyperechoic (type IV). ${ }^{5}$ The functional assessment included the peak systolic velocity (PSV) of the carotid artery. Data was collected after obtaining ethical approval from the Research Ethics Committee Universitas Padjadjaran (790/UN6.KEP/EC/2020) and
Dr. Hasan Sadikin General Hospital Bandung (LB.02.01/X.2.2.1/19917/2020). Data were presented in tables.

\section{Results}

During the study period, 116 ischemic stroke patients underwent carotid Doppler examination. Of these, 73 data were excluded because the type of stroke did not meet the inclusion criteria. Of the 43 eligible data, 5 data were excluded due to incomplete data, so that the remaining 38 records were eligible for analysis.

The median age for ischemic stroke was 59 years (range 49-64), with female patients out numbering male patients (60.5\% vs $39.5 \%)$. The carotid system involved in ischemic stroke was found to be almost the same between the right and left carotid systems (Table 1).

Among 38 patients, plaque was found in 18 patients (12 in right carotid system only, 14 in the left, and 8 patients had plaque in both systems). The presence of plaque was slightly more common in the left carotid system. The most common plaque type found in both systems was type III $(66.7 \%$ on the right, $50.0 \%$ on the left), followed by type II $(25.0 \%$ on the right, $42.9 \%$ on the left). Type I plaques were found in 1 right carotid system (8.3\%) and type IV plaques in 1 left carotid system (7.1\%). Nearly all plaques were found in the common carotid artery $(88.3 \%$ on the right, $92.9 \%$ on the left), and only a small proportion in the internal carotid artery.

Intimal media thickening was found in 5 right carotid systems (13.2\%) and 6 left carotid systems (15.8\%). Stenosis was present in $34.2 \%$ of patients. Among patients with stenosis, most of them had $<50 \%$ stenosis (Table 2).

Functional assessment showed that there was an increase in PSV in a minority of the patient's internal carotid arteries $5.3 \%$ on the

Table 1 Ischemic Stroke Patients Characteristics $(n=38)$

\begin{tabular}{lc}
\hline \multicolumn{1}{c}{ Characteristics } & $\mathbf{n ( \% )}$ \\
\hline Age (years)-median (IQR) & $59(49-64)$ \\
Gender, n (\%) & \\
$\quad$ Male & $15(39.5)$ \\
$\quad$ Female & $23(60.5)$ \\
Stroke system, n (\%) & \\
$\quad$ Right carotid system & $18(47.4)$ \\
$\quad$ Left carotid system & $20(52.6)$ \\
\hline
\end{tabular}


Table 2 Anatomical Assessment of Carotid Doppler Examination $(n=38)$

\begin{tabular}{|c|c|c|c|}
\hline \multicolumn{2}{|c|}{ Carotid Doppler Examination Report } & $\begin{array}{c}\text { Right carotid system } \\
\text { n(\%) }\end{array}$ & $\begin{array}{l}\text { Left carotid system } \\
\text { n(\%) }\end{array}$ \\
\hline \multicolumn{4}{|l|}{ Atherosclerotic plaque } \\
\hline Present* & & $12(31.6)$ & $14(36.8)$ \\
\hline Absent & & $26(68.4)$ & $24(63.2)$ \\
\hline \multicolumn{4}{|l|}{ Plaque type** } \\
\hline Type I & & $1(8.3)$ & $0(0)$ \\
\hline Type II & & $3(25)$ & $6(42.9)$ \\
\hline Type III & & $8(66.7)$ & $7(50)$ \\
\hline Type IV & & $0(0)$ & $1(7.1)$ \\
\hline \multicolumn{4}{|l|}{ Plaque location $* *$} \\
\hline Common carotid artery & & $10(83.3)$ & 13(92.9) \\
\hline Internal carotid artery & & $2(16.7)$ & $1(7.1)$ \\
\hline \multicolumn{4}{|l|}{ Thrombus } \\
\hline Present & & $0(0)$ & $0(0)$ \\
\hline Absent & & $38(100)$ & $38(100)$ \\
\hline \multicolumn{4}{|l|}{ Intimal media thickening } \\
\hline Present & & $5(13.2)$ & $6(15.8)$ \\
\hline Absent & & $33(86.8)$ & $32(84.2)$ \\
\hline \multicolumn{4}{|l|}{ Stenosis } \\
\hline$<50 \%$ & & 11(29) & $12(31.6)$ \\
\hline $50-70 \%$ & & $1(2.6)$ & $0(0)$ \\
\hline $70-95 \%$ & & $1(2.6)$ & $0(0)$ \\
\hline $95-99 \%$ & & $0(0)$ & $1(2.6)$ \\
\hline$>99 \%$ & & $0(0)$ & $0(0)$ \\
\hline No stenosis & & $25(65.8)$ & $25(65.8)$ \\
\hline \multicolumn{4}{|c|}{$\begin{array}{l}\text { Note: }{ }^{*}=8 \text { patients had bilateral plaques, }{ }^{* *}=\mathrm{n} \text { subjects were } 12 \text { in the right carotid system and } 14 \text { in the left caroti } \\
\text { system }\end{array}$} \\
\hline \multicolumn{2}{|c|}{ Peak Systolic Velocity (PSV) } & $\begin{array}{c}\text { Right carotid system } \\
\text { n(\%) }\end{array}$ & $\begin{array}{c}\text { Left carotid system } \\
\text { n(\%) }\end{array}$ \\
\hline \multicolumn{4}{|l|}{ Location } \\
\hline Common carotid artery & $\begin{array}{l}<125 \mathrm{~cm} / \mathrm{s} \\
>125 \mathrm{~cm} / \mathrm{s}\end{array}$ & $\begin{array}{l}38(100) \\
0(0)\end{array}$ & $\begin{array}{l}38(100) \\
0(0)\end{array}$ \\
\hline Internal carotid artery & $\begin{array}{l}<125 \mathrm{~cm} / \mathrm{s} \\
>125 \mathrm{~cm} / \mathrm{s}\end{array}$ & $\begin{array}{l}36(94.7) \\
2(5.3)\end{array}$ & $\begin{array}{l}35(92.1) \\
3(7.9)\end{array}$ \\
\hline
\end{tabular}

right and $7.9 \%$ on the left). Common carotid artery blood flow was within normal limits in all subjects (Table 3 ).

\section{Discussion}

Stroke incidence and atherosclerotic plaque formation increases with age, with the highest incidence at age 60 years or older. The median age in this study was 59 years, in accordance with previous studies where most of the patients belonged to the age group of 60-69 years. ${ }^{8,9}$ The incidence was more common in women, in contrast to what was found in the Riskesdas 2018 which revealed that the incidence was almost the same between men and women. ${ }^{3}$ Most of the patients had left carotid system stroke. This finding is different from 2 studies conducted in South India, where in the first study, most of the patients had right system stroke, and another study showed the equal numbers of right and left system stroke patients. ${ }^{6,9}$ Another study in the United States of America showed similar results to this study, in which left-hemispheric anterior circulation ischemic strokes were 
slightly more common than right-hemispheric stroke. ${ }^{10}$ These data revealed that there was no significant difference between the incidence of right and left carotid system strokes. Left system stroke has a slightly higher incidence due to hemodynamic differences in the left carotid artery, the direct branch of the aorta, where there is higher stress and intimal damage. ${ }^{10}$

This study specifically involved ischemic stroke patients with atherothrombotic or thromboembolic origin. However, majority of patients had no signs of atherosclerotic plaque in the carotid arteries. This finding differs from previous evidence in which the extracranial carotid artery was the most common plaque location. ${ }^{4,11}$ This is probably due to ethnic differences, where atherosclerotic lesions in Asian people are more frequently found in the intracranial vessels. ${ }^{12}$ The causes are still unknown but presumably related to genetics and nutritional factors. ${ }^{12} \mathrm{~A}$ study in the South Korea showed that patients with the genetic variant RNF213, one of the most susceptible genes for Moyamoya disease among East Asians, was associated with an increased risk and early onset of intracranial atherosclerotic disease. $^{13}$ However, study in China shows that the incidence is also different within the country. A higher incidence was found in areas of a more westernized lifestyle, indicating that nutritional factors also play a role in the intracranial lesions formation. ${ }^{14}$

In patients with atherosclerotic plaques, plaque characteristics were then assessed. This study has similar findings to a study in India which showed that more plaque is located in the common carotid artery.11 Vulnerable plaque, indicated as plaque with a high degree of echolucency, is prone to rupture and may result in thrombus formation. In this study, the most common plaque found was type III, followed by type II, indicating that the plaque found was more stable. ${ }^{5}$ This could explain the total absence of thrombus in this study. The presence of plaque that was more stable in this study was probably due to the fact that the subjects of this study were stroke patients, while other studies mostly reported plaque formation in non-stroke subjects to predict the stroke incidence. Vulnerable plaque could have already ruptured, causing an embolism leading to the diagnosis of an ischemic stroke. Previous studies have also shown a strong correlation between echolucent plaques and an increased risk of ipsilateral stroke in asymptomatic carotid artery stenosis patients. ${ }^{15}$

Intimal media thickening of carotid artery might be present as the earliest sign of progressive atherosclerosis. ${ }^{16}$ In this study, patients were classified as having intimal media thickening when the intimal media thickness found was $>1.00 \mathrm{~mm}$. Most patients had normal intimal media thickness. Stenosis was found in a minority of patients. Previous studies have shown that carotid stenosis is clinically important if the stenotic degree is $>60 \% .{ }^{7}$ In this study, most of the patients with stenosis were included in the criteria for insignificant stenosis $(<50 \%)$. This finding is similar to a study conducted in India, where most of the subjects had $<50 \%$ stenosis. ${ }^{6,17}$

One of the most accurate predictors of internal carotid artery stenosis is the PSV assessment. ${ }^{9}$ Previous studies have shown that PSV $>125 \mathrm{~cm} / \mathrm{s}$ is correlates with $>60 \%$ stenosis of the carotid artery, which is clinically important. ${ }^{7}$ Most of the patients in this study had normal results in their PSV assessment in the common and internal carotid arteries.

This study has several limitations. First, carotid Doppler ultrasound has not yet become part of the standard examination performed in patients with atherothrombotic ischemic stroke, so data are still scarce. Besides, it was done in a single medical center with a limited period of time, hence, the sample size was small and might not represent the actual condition. Second, this study did not record risk factors that could have interfered with the findings. Third, data on the involvement of patients with stroke system in this study were obtained from the referral doctor's statement, not directly from the results of brain imaging. Further studies are suggested to have a larger sample size and risk factors assessment so that more precise results can be obtained.

To conclude, most of the atherothrombotic and thromboembolic type ischemic stroke patients in this study have normal carotid Doppler ultrasound features. Among patients with pathological changes, most prevalent changes found are atherosclerotic plaques, with type III plaques and located in the common carotid artery. Further studies comparing the presence of extracranial and intracranial plaques among Indonesian are needed.

\section{References}

1. Turana Y, Tengkawan J, Chia YC, Nathaniel M, Wang JG, Sukonthasarn A, et al. Hypertension and stroke in Asia: a comprehensive review from HOPE Asia. J Clin Hypertens. 2020;00:1-9. 
2. Sacco RL, Kasner SE, Broderick JP, Caplan LR, Connors JJ, Culebras A, etal. An updated definition of stroke for the 21st century: a statement for healthcare professionals from the American heart association/ American stroke association. Stroke. 2013;44(7):2064-89.

3. Kementerian Kesehatan Republik Indonesia. Riset Kesehatan Dasar (Riskesdas) 2018. Jakarta; Kementerian Kesehatan Republik Indonesia 2018.

4. Hossmann K-A, Heiss W-D. Neuropathology and pathophysiology of stroke. In: Brainin M, Heiss W-D, editors. Textbook of stroke medicine. $3^{\text {rd }}$ ed. Cambridge, UK: Cambridge University Press; 2019. p. 1-37.

5. Marques MD, Lima JAC. Current imaging approaches and challenges in the assessment of coronary artery disease. In: Yuan C, Hatsukami T, Mossa-Basha M, editors. Vessel based imaging techniques. Cham, Switzerland: Springer. 2020. p.229244.

6. ChamarthiM, Kumar L, Nirusha R, Pravallika I, Kejriwal GS. Color doppler evaluation of carotid arteries in stroke patients: A study conducted in a rural tertiary care medical college hospital in South india. IOSR J Dent Med Sci. 2017;16(01):04-9.

7. László C. Ultrasound in acute ischemic stroke. In: Brainin M, Heiss WD, editors. Textbook of stroke medicine. $3^{\text {rd }}$ ed. Cambridge, UK: Cambridge University Press; 2019. p. 90-107.

8. 8Boehme AK, Esenwa C, Elkind MSV. Stroke risk factors, genetics, and prevention. Circ Res. 2017;120(3):472-95.

9. Fernandes M, Keerthiraj B, Mahale AR, Kumar A, Dudekula A. Evaluation of carotid arteries in stroke patients using color Doppler sonography: A prospective study conducted in a tertiary care hospital in South India. Int J Appl Basic Med Res. 2016;6(1):38-44.

10. Hedna VS, Bodhit AN, Ansari S, Falchook AD, Stead L, Heilman KM, et al. Hemispheric differences in ischemic stroke: Is lefthemisphere stroke more common? J Clin Neurol. 2013;9(2):97-102.

11. Pathak MR, Gautam M, Pathak YR. Evaluation of extracranial carotid arteries in ischemic stroke patients using color Doppler sonography and correlation with various risk factors. J Nobel Med Coll. 2019;8(2):10-4.

12. Arboix A. Cardiovascular risk factors for acute stroke: Risk profiles in the different subtypes of ischemic stroke. World J Clin Cases. 2015;3(5):418-29.

13. Bang OY, Chung JW, Cha J, Lee MJ, Yeon JY, Ki CS, et al. A polymorphism in RNF213 is a susceptibility gene for intracranial atherosclerosis. PLoS One. 2016;11(6):e0156607.

14. Ritz K, Denswil NP, Stam OCG, Van Lieshout JJ, Daemen MJAP. Cause and mechanisms of intracranial atherosclerosis. Circulation. 2014;130(16):1407-14.

15. Paraskevas KI, Veith FJ, Spence JD. How to identify which patients with asymptomatic carotid stenosis could benefit from endarterectomy or stenting. Stroke Vasc Neurol. 2018;3(2):92-100.

16. Haq S, Mathur M, Singh J, Kaur N, Sibia RS, Badhan R. Colour doppler evaluation of extracranial carotid artery in patients presenting with acute ischemic stroke and correlation with various risk factors. J Clin Diagn Res. 2017;11(3):TC01-5.

17. Ramasamy M, Rao AD, Radhakrishnan S. Color Doppler evaluation of carotid arteries in cerebral ischemia. Int J Contemp Med Surg Radiol. 2020;5(3):C57-61. 